\title{
Effect of number of layers on coir geotextile reinforced sand under cyclic loading
}

\author{
R. Sridhar ${ }^{1 *}$ (I) and M. T. Prathap Kumar ${ }^{2}$
}

\author{
*Correspondence: \\ sridharrajagopalg@gmail. \\ com \\ ${ }^{1}$ Department of Civil \\ Engineering, Sri \\ Venkateswara College \\ of Engineering, Bengaluru, \\ Karnataka, India \\ Full list of author information \\ is available at the end of the \\ article
}

\begin{abstract}
The present investigation is on the behavior of coir geotextile-reinforced sandy soil foundations and to study the effect of different parameters contributing to their performance using laboratory model tests. The parameters investigated in this study included top layer spacing, number of reinforcement layers and vertical spacing between layers. The effect of coir geotextile reinforcement on the vertical stress distribution in the sand and the strain distribution along the reinforcement were also investigated. The test results established the potential benefit of using coir geotextilereinforced sand foundations. The test results also showed that the reinforcement configuration/layout has a significant effect on the behavior of reinforced sand foundation. With two or more layers of reinforcement, the settlement can be reduced at all footing pressure levels. The inclusion of reinforcement can redistribute the applied footing load to a more uniform pattern, hence reducing the stress concentration, which will result reduced settlement.
\end{abstract}

Keywords: Cyclic stress ratio, Cyclic settlement, Coir geotextile

\section{Introduction}

Reinforcing soil under the foundations is becoming a reliable technique due to the advent of materials such as grids/mats that can be made of both natural and synthetic materials. Natural products such as coir mats and coir grids with are emerging as viable reinforcing material, when introduced in the soil. Reinforced soil has performed satisfactory under monotonic/static loadings. Several literatures are available support the above fact [1].

Structural engineers come across situations wherein live loads in a structure may be greater than the dead load of the structure itself. Further these kinds of live loads are also found to change with time, thereby subjecting the underlying soil to the repeated or cyclic loads. Thus the performance of foundations under such situations mainly depends on frequency and amplitude of the cyclic loading. Further, foundations are also subjected to vibrations during seismic activity as well as foundations under machines. Studies on performance of footings under cyclic loading are very few in literatures Gray and Ohashi [2], Chang et al. [3], Gray. and Talal Al-Refeai [4], Guido et al. [5], Raymond \& comos [6], Wasti and Butun (1996), Chen et al. [7]. The application of reinforced soil under cyclic load has enormous potential in many applications of civil engineering. It shall be noted that the settlements under cyclic loads are far greater than those produced under static

(c) The Author(s) 2018. This article is distributed under the terms of the Creative Commons Attribution 4.0 International License (http://creativecommons.org/licenses/by/4.0/), which permits unrestricted use, distribution, and reproduction in any medium, provided you give appropriate credit to the original author(s) and the source, provide a link to the Creative Commons license, and indicate if changes were made. 
loads by [8-16]. The overall behavior of the reinforced mass depends on the reinforcement material.

Reinforcement when introduced into soil and aligned in the direction of the tensile strain arc disrupts the uniform pattern of strain that would develop if the reinforcement did not exist. The reinforcement also inhibits the formation of continuous rupture surfaces through the soil, resulting in improved stiffness and shear strength. Jewell [17] has shown the improved behaviour of reinforced dense sand.

The Properties of reinforcement, soil characteristics and the nature of the interaction between the soil and the reinforcement influences the performance of the reinforced soil. The interaction mechanism is affected by factors such as: state of stress within the reinforced mass; nature of loading; direction of reinforcement; boundary conditions; and material and interface properties. In the case of monotonic loading, three mechanisms of interaction have been identified: passive anchorage; enhanced confinement; and tensile membrane action. Under cyclic loading conditions, other mechanisms such as dynamic interlock have been observed [18]. Shin et al. [19] investigated the prospect of reinforcing geogrid layers in soil to reduce the settlement of a railroad bed and subballast layer subjected to cyclic load. Moghaddas Tafreshi and Dawson [20] found when reinforcement were placed in optimum depth from the surface of footings such as strip, square, rectangular foundations, the maximum advantage of reinforcement in bearing capacity was obtained. Naeini and Gholampoor [21] investigated number of cyclic triaxial tests on specimens of $70 \mathrm{~mm}$ diameter to study the cyclic performance of dry silty sand reinforced with a geotextile. Factors affecting the cyclic behavior, viz. the arrangement and number of geotextile layers, confining pressures and silt content were varied in the tests. It was concluded that geotextile reinforcement causes considerable increase in the cyclic axial modulus of dry sand and sand mixed with varying amounts of silt and the effect was more prominent when the geotextile was placed near the surface of the sample.

This tendency indicates that the reinforced soil behaves in a different manner under cyclic loading. Hence a clear understanding of the mechanism or settlement of reinforced soil under cyclic loading needs to be understood. Hence in the present experimental investigation a natural bi-product such as coir mat has been used as reinforcement and experimental studies using model footings subjected to cyclic loading resting on reinforced sand beds is proposed to understand the settlement behavior of footings and number of layers of reiforcement under cyclic loading with different excitation parameters.

\section{Materials}

The sand used in the present investigation is locally available medium silica river sand, dried and sorted by particle sizes. The sand was sieved through $1 \mathrm{~mm}$ IS sieve in order to make it a uniformly graded, to minimize effect of segregation during preparation of the sand bed. Table 1 shows the properties of sand used.

Coir mat procured from Karnataka coir Federation, Bangalore was used in the present study. The size of the opening of the coir mat was kept equal to $20 \times 20 \mathrm{~mm}$. It was found from direct shear test results that the coir mat opening of size $20 \times 20 \mathrm{~mm}$ gave 
Table 1 Properties of sand used

\begin{tabular}{lc}
\hline Property & Values \\
\hline Specific gravity, $\mathrm{G}$ & 2.67 \\
Coefficient of uniformity, $\mathrm{C}_{u}$ & 1.4 \\
Coefficient of curvature, $\mathrm{Cc}$ & 1.03 \\
Effective diameter of particle, $\mathrm{D}_{10}(\mathrm{~mm})$ & 0.2 \\
Maximum dry density $\left(\mathrm{kN} / \mathrm{m}^{3}\right)$ & 18.7 \\
Minimum dry density $\left(\mathrm{kN} / \mathrm{m}^{3}\right)$ & 14.7 \\
Compacted density $\left(\mathrm{kN} / \mathrm{m}^{3}\right)$ & 16.9 \\
Relative density $\left(\mathrm{kN} / \mathrm{m}^{3}\right)$ & 60 \\
Elastic modulus $(\mathrm{MPa})$ & 30 \\
\hline
\end{tabular}

Table 2 Mechanical properties of coir mat used

\begin{tabular}{ll}
\hline Mass/unit area $\left(\mathrm{g} / \mathrm{m}^{2}\right)$ & 835 \\
Thickness $(\mathrm{mm})$ & 6.81 \\
Yarn count & $2 / 0.24^{5}$ \\
Direction A (Ne) & $2 / 0.22^{5}$ \\
Direction B (Ne) & \\
No. of yarns $/ \mathrm{dm}$ & 7 \\
Direction A/dm & 9 \\
Direction A/dm & \\
Yarns twist (Turns/m) & 73 \\
Direction A & 63 \\
Direction B & 10.8 \\
Cover factor & 252 \\
Breaking load $(\mathrm{N})$ & 31 \\
Elongation $(\%)$ & \\
\hline
\end{tabular}

optimum value of internal friction [22] The typical properties of the coir mats are as shown in Table 2.

\section{Methodology}

\section{Preparation of the sand bed}

In the present investigation, sand bed was compacted in the test tank by raining technique to attain a compacted density of $16.9 \mathrm{kN} / \mathrm{m}^{3}$ with a relative density of $60 \%$. Predetermined weight of sand was poured using a funnel from a specified height so that the essential relative density of $60 \%$ is achieved. The sand was spread uniformly during pouring in layers. Uniformly distributed blows of about 20 numbers using a standard $4.5 \mathrm{~kg}$ rammer falling though a height of $45 \mathrm{~cm}$ were also given to level of compacted sand. Empty cups were placed during filling to determine the density of the sand in the cup. Several trials were done to determine the height of fall of sand to keep the uniformity in compaction to give the desired relative density. Figure 1 shows the pouring of sand in the test tank by raining technique.

For the case of unreinforced sand, the sand was compacted in three layers of equal height. For the case of reinforced sand, coir mat was placed so that specified clearance of about $40 \mathrm{~mm}$ from the sides of tank was maintained in order to avoid side friction. 


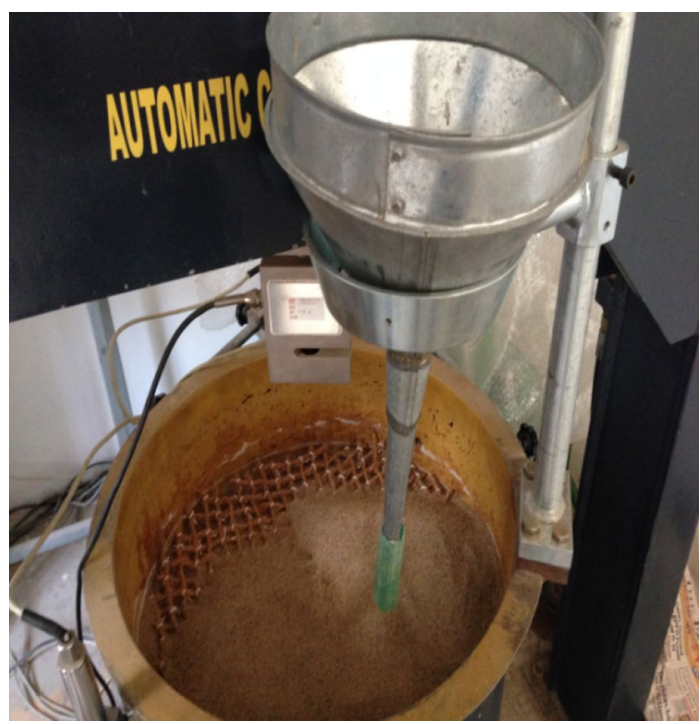

Fig. 1 Pouring of sand in test tank

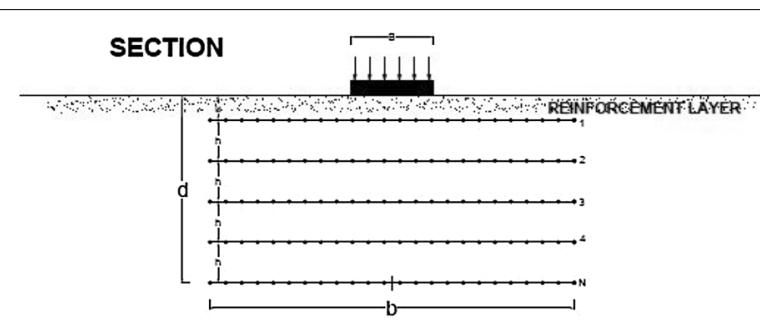

PLAN

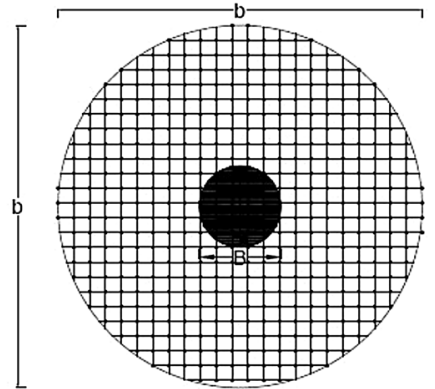

Fig. 2 Plan and section of placement of number layers of coir mat in sand

The configuration of coir mat reinforcement used in the investigation was shown in Fig. 2 placed in number of layers $\mathrm{NL}=1,2,3$ and 4 and the details of the parameters are as shown in the Table 3 . To represent the practical situation regarding ratio of model footing and tank size used, followed the procedure as per IS: 1888 (1982) and the load increment was maintained until the rate of settlement reduced to a value $0.02 \mathrm{~mm} / \mathrm{min}$.

The footing of diameter $100 \mathrm{~mm}$ was placed on the surface of the sand bed and cyclic load was applied using hydraulic actuator placed vertically in line with load cell and piston. Both reinforced and unreinforced sand beds were subjected to cyclic 
Table 3 Configuration of coir mat reinforcement

\begin{tabular}{|c|c|c|c|c|c|c|c|}
\hline \multicolumn{5}{|c|}{ Reinforcement distribution } & \multicolumn{3}{|c|}{ Excitation parameters } \\
\hline $\begin{array}{c}\text { Type of Rein- } \\
\text { forcement }\end{array}$ & $\mathrm{u} / \mathrm{B}$ & $\mathrm{b} / \mathrm{B}$ & $h / B$ & No. of layers (NL) & Waveform type & Frequency $\mathrm{Hz}$ & Cyclic pressure $\mathrm{kPa}$ \\
\hline Reinforced & $0.3,0.6,1.0$ & 4.4 & - & $1,2,3,4$ & Sine & $0.5,1.0,1.5$ & $100,200,300$ \\
\hline
\end{tabular}

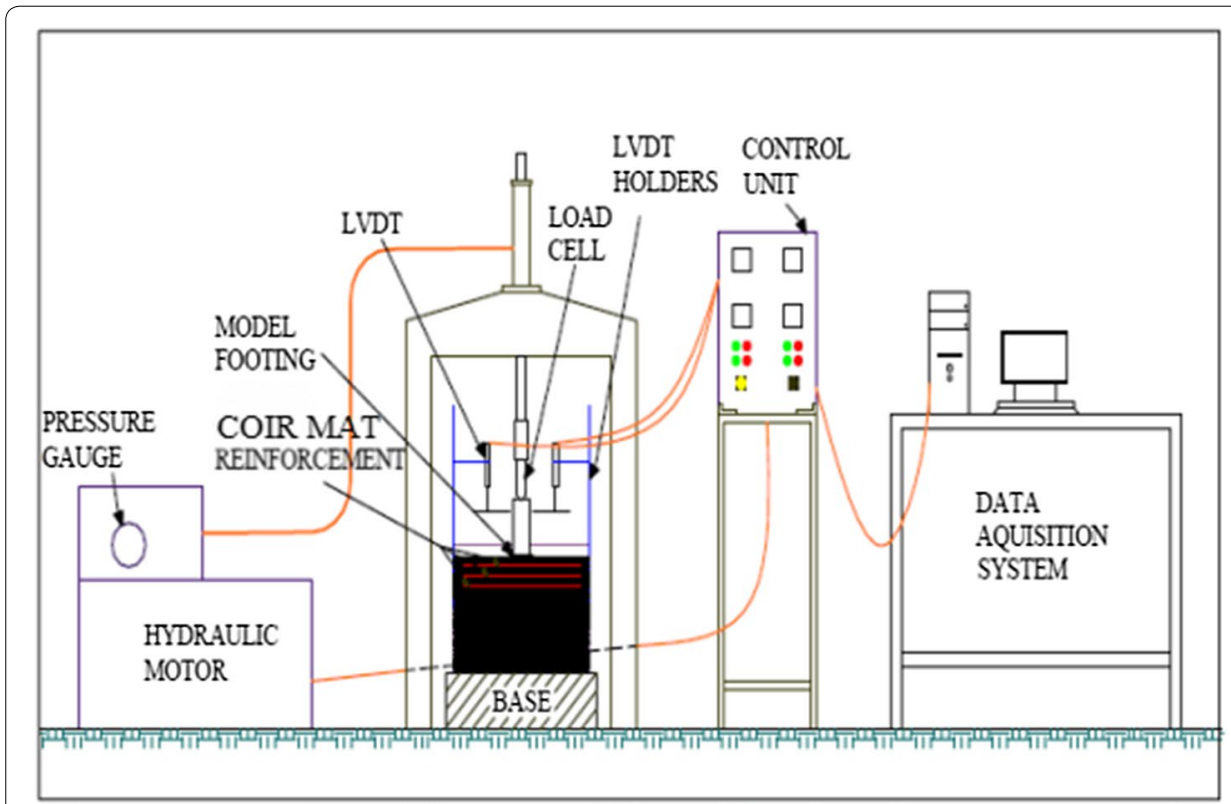

Fig. 3 Schematic diagram of test setup used in the present investigation

loading. The excitation values such as type of wave form, frequency and cyclic pressure were fed as input values using MOVICON 11.2 software.

In the present investigation, half wave sine form was used throughout the loading of the model footing. Tests were done under a constant cyclic pressure of 100, 200 and $300 \mathrm{kPa}$ and under each constant cyclic pressure; the frequency of the sine wave was varied from $0.5,1$ and $1.5 \mathrm{~Hz}$. Figure 3 shows schematic diagram of entire test setup used in the present investigation. For very lightly loaded footings the natural frequency is almost independent of the footing size for a given load intensity, but for high loads it is almost inversely proportional to the foundation width. For inundated foundations the natural frequencies were again almost independent of the footing shape at low load intensities, but the frequencies were only a little over half those on the dry sand. At high loads the frequency was again roughly inversely proportional to the footing width but was not nearly so low relative to the value for a corresponding footing on dry sand as it was at low load intensities [23].

Series of such test were conducted for reinforced sand bed with number of layers being varied from 1, 2, 3 and 4. The layers of mat reinforcement were positioned at specified locations and load tests were done until the cyclic settlements showed sudden increase indicating significant penetration of the model footing after certain 
number of load cycles. Tests results were plotted as variation of number of cycles on log scale with corresponding cyclic settlements to determine and analyze the effect of number of layers as well as to assess the comparative performance of coir mat reinforced sand with unreinforced sand.

\section{Cyclic load settlement behavior of unreinforced sand}

The results of the cyclic loading test on model footings resting on unreinforced sand and coir mat reinforced sand with coir mat placed at different configurations have been presented. Analysis of the results under different excitation parameters such as effect of frequency, effect of amplitude of loading in terms of cyclic pressure is determined.

The test results recorded for model footing resting on unreinforced sand and at excitation parameters such as frequency $(F)=0.5 \mathrm{~Hz}$ and cyclic pressure $(\mathrm{CP})=100$, 200 and $300 \mathrm{kPa}$. Figure 4 shows the typical variation of number of cycles versus cumulative cyclic settlement, henceforth called as cyclic settlement at $\mathrm{F}=0.5,1$ and $1.5 \mathrm{~Hz}$ and at $\mathrm{CP}=100,200$ and $300 \mathrm{kPa}$. It can be seen from Fig. 4 that for a constant frequency of $0.5 \mathrm{~Hz}$, increase in cyclic pressure increases settlement. From these plots, it can be inferred that for a given frequency and cyclic pressure, the rate of settlement increases after a certain number of cycles are reached.

The unreinforced sand is set to yield at approximately number of cycles $\mathrm{N}=2000$ corresponding to $\mathrm{F}=0.5 \mathrm{~Hz}$ and $\mathrm{CP}=100 \mathrm{kPa}$. Similar trends have been obtained for unreinforced sand tested under different frequencies and different cyclic pressures, in all these cases it can be seen that with increase in cyclic pressure and at a constant frequency the number of cycles required to cause yielding decreases. Figure 4 shows such a variation where it can be seen that for a given constant frequency increase in cyclic pressure causes soil to yield at a smaller number of cycles. Similarly for a constant cyclic pressure increase in frequency causes soil to yield at lower value of number of cycles.

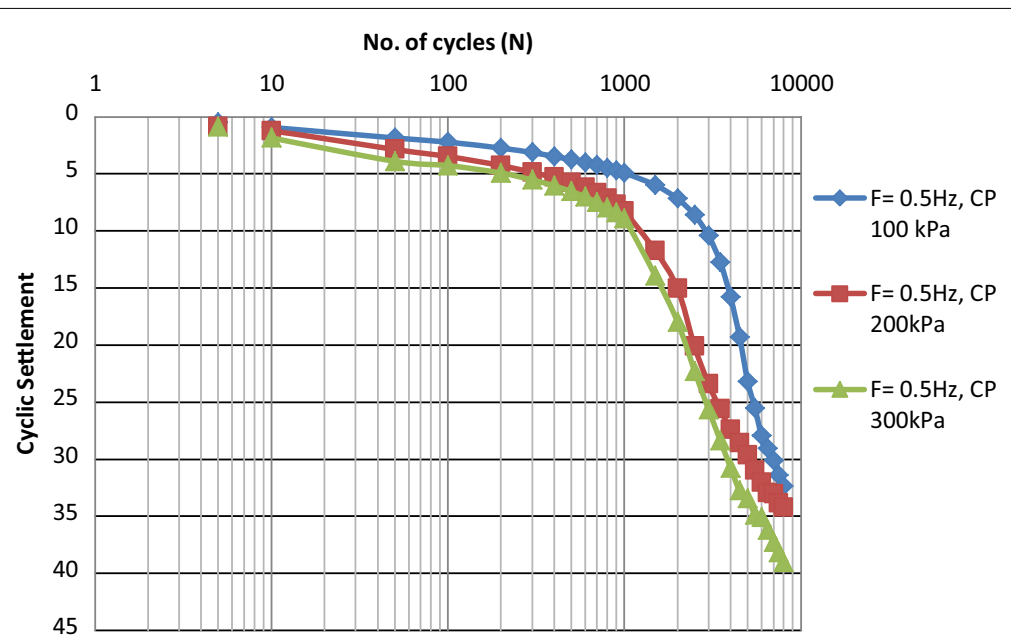

Fig. 4 Variation of cyclic settlement with cumulative number of cycles for frequency $0.5 \mathrm{~Hz}$ and varying cyclic pressure for unreinforced sand 
Table 4 CSR values for $\mathrm{NL}=1$ and $\mathrm{CP}=100 \mathrm{kPa}$ under varying frequency

\begin{tabular}{|c|c|c|c|c|c|c|c|c|c|}
\hline \multicolumn{10}{|l|}{$\mathrm{CSR}_{\mathrm{N}=1}$} \\
\hline \multirow[t]{3}{*}{ Settlement } & \multicolumn{9}{|c|}{$\mathrm{NL}=1 ; \mathrm{CP}=100 \mathrm{kPa}$} \\
\hline & \multicolumn{3}{|l|}{$0.5 \mathrm{~Hz}$} & \multicolumn{3}{|l|}{$1.0 \mathrm{~Hz}$} & \multicolumn{3}{|l|}{$1.5 \mathrm{~Hz}$} \\
\hline & Reinforced & Unreinforced & CSR & Reinforced & Unreinforced & CSR & Reinforced & Unreinforced & CSR \\
\hline 5 & 4000 & 1000 & 4.00 & 1700 & 500 & 3.40 & 1250 & 50 & 25.00 \\
\hline 10 & 20,000 & 2800 & 7.14 & 15,000 & 1000 & 15.00 & 11,500 & 700 & 16.43 \\
\hline 15 & 30,000 & 3800 & 7.89 & 31,000 & 1400 & 22.14 & 28,000 & 950 & 29.47 \\
\hline 20 & 68,000 & 4600 & 14.78 & 51,000 & 1750 & 29.14 & 47,000 & 1300 & 36.15 \\
\hline 25 & 100,000 & 5400 & 18.52 & 70,000 & 2500 & 28.00 & 65,000 & 1900 & 34.21 \\
\hline
\end{tabular}

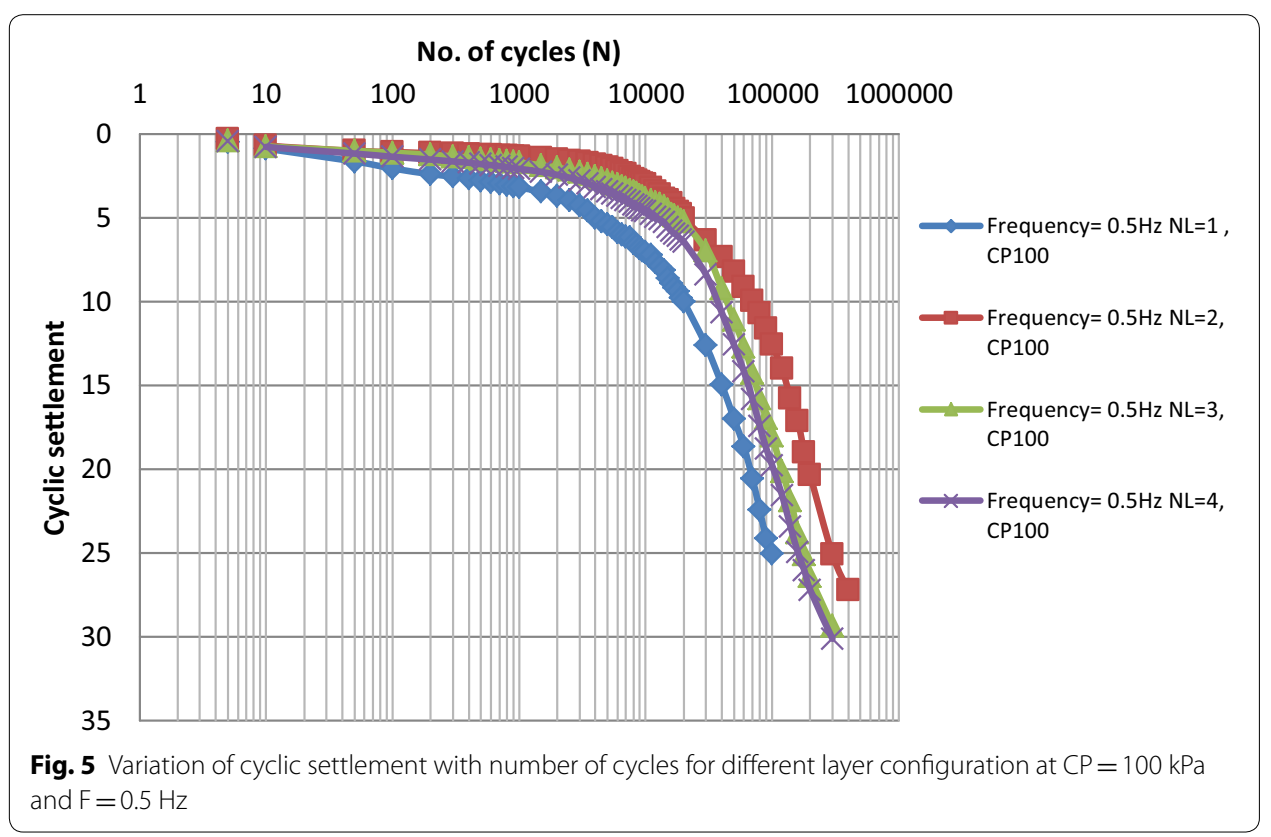

\section{Cyclic load settlement behaviour of reinforced sand}

Cyclic load were also applied for model footings resting on reinforced sand bed by placing single layer, two layers, three layers and four layers as per the test configuration shown in Table 4, to determine effect of frequency and amplitude of cyclic loading. The results were analyzed to determine optimum number of layers, that are most beneficial in reducing the settlement as well as increasing the number of load cycles before yielding and hence to increase the cyclic load carrying capacity of reinforced sand.

Figure 5 shows typical variation of cyclic settlement with number of cycles for different layers configuration used in the present study. It can be seen from all these figures that for a constant frequency and constant amplitude in terms of CP the sand reinforced with $\mathrm{NL}=2$ has been more effective in resisting cyclic load compared to $\mathrm{NL}=1,3$ and 4 layers. The sand with $\mathrm{NL}=1$ is the least resistant as the cyclic settlement recorded corresponding to different cycles of loading is significantly large when compared with 2, 3 and 4 layers. Further the cyclic settlement recorded for reinforced sand with $\mathrm{NL}=3$ and 4 shows marginal variations in cyclic settlement with number of cycles between them. 
Also for a given number of load cycles the cyclic settlement recorded for $\mathrm{NL}=3$ and 4 are higher than those recorded for $\mathrm{NL}=1$ layer for a constant frequency and cyclic pressure.

The reason for the above trend can be attributed to the following: It is known that provision of reinforcement increases stiffness of the sand. Further mat or grid form of reinforcement provides inter locking effect, by locking the sand particles in the space/ grid of the reinforcement. This restrains the lateral movement of the soil particles, causing increased cyclic resistance of reinforced sand. However, the increased cyclic resistance also depends on location or position of the reinforcement below the model footing. Due to repeated load cycles on the geogrid-reinforced soil beds, the soil particles are locked into the apertures of mat during the loading stage and prevent the full recovery of elastic and time-dependent strains to develop during the unloading stage. This is concept is known as "Dynamic Interlock". The dynamic interlock in soil structures induces soil confining stresses as a result of the compaction process, which strengthens the reinforced soil medium. In the present experimental investigation number of layers were varied from $1,2,3$ and 4 by varying $\mathrm{u} / \mathrm{B}=0.3$ and $\mathrm{h} / \mathrm{B}$ ratio was kept constant $=0.5$ between different layers. The trend in the results indicates that the introduction of two layered reinforcement is more effective. This is due to the fact that, when two layers are placed with $\mathrm{u} / \mathrm{B}=0.3$ and $\mathrm{h} / \mathrm{B}=0.5$ it will lie in the probable shear failure zone below the model footing. Theoretically the depth of the shear failure zone will extend to a depth of 0.5-1.2 B, depending on angle of internal friction of compacted sand. For other layer configurations such as for $\mathrm{NL}=3$ and 4 , the third and fourth layer may be located below the shear failure zone. Thus the trend in test results clearly indicates that $\mathrm{NL}=2$ is most effective in increase in cyclic resistance. However, it can also be noted that introduction of reinforcement causes a significant increase in cyclic resistance when compared to unreinforced sand as the number of load cycles required for the soil to yield is significantly larger when compared with that obtained for unreinforced sand. The rate of change of peak settlement and residual settlement reduces as the number of cycles increases and that a small reduction in amplitude (i.e. the difference between these two settlements) is also apparent. Often, the variation of settlement becomes stable after number cycles. This stabilizing response indicates that the early process of reorientation of particles, causing local fill stiffening, ceases relative rapidly and the system then reaches the "plastic shakedown" condition defined by Werkmeister et al. [24], in which subsequent deformation is fully recovered in each cycle. These values entail that the relative decrease in footing settlement for a variation of $\mathrm{N}$ between 1 and 2 is significantly greater than those for variation of $\mathrm{N}$ between 2 and 4. Despite the fact that the mass used for $\mathrm{N}=1$ and $\mathrm{N}=2$ are, respectively, two and four times of $\mathrm{N}=1$. Moghaddas Tafreshi and Khalaj [25] investigated the decrease in the settlement of the overlying soil surface under repeated loads can be reduced significantly by using geogrid reinforcement, while the effectiveness of the reinforcement was decreased by increasing the number of reinforcement layers.

\section{Effect of frequency of cyclic loading}

Figure 6 shows effect of frequency of cyclic loading with number of layers. It clearly shows that with $\mathrm{NL}=2$ layers there is a significant reduction in settlement with a 

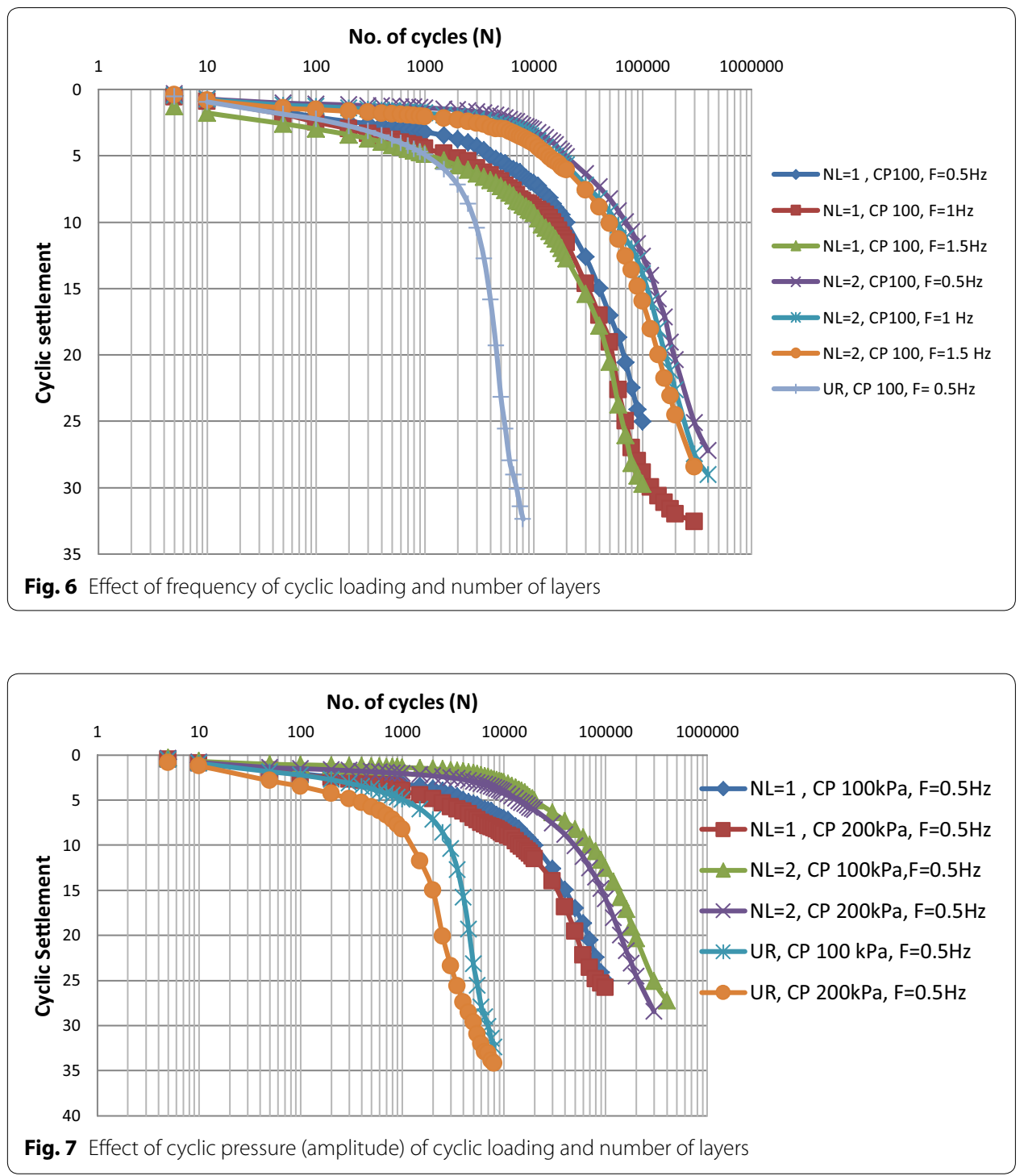

corresponding increase in number of load cycles required to cause yield. Further it can also be seen that the cyclic resistance of unreinforced sand is significantly lower than those for reinforced sand. With increase in frequency of cyclic loading the number of cycles required to cause yielding of sand decreases, which is in confirmation with earlier literatures.

\section{Effect of cyclic pressure}

Figure 7 shows variation of cyclic settlement with number of cycles at different cyclic pressure. It can be seen that increase in cyclic pressure/amplitude of cyclic loading increases the cyclic settlement for a constant frequency of $0.5 \mathrm{~Hz}$. Thus increase in amplitude of cyclic loading causes the soil to yield at earlier cycles and the trend in results once again indicates that $\mathrm{NL}=2$ layers is more effective in retarding cyclic settlement under all excitation parameters such as frequency and amplitude of cyclic loading. 


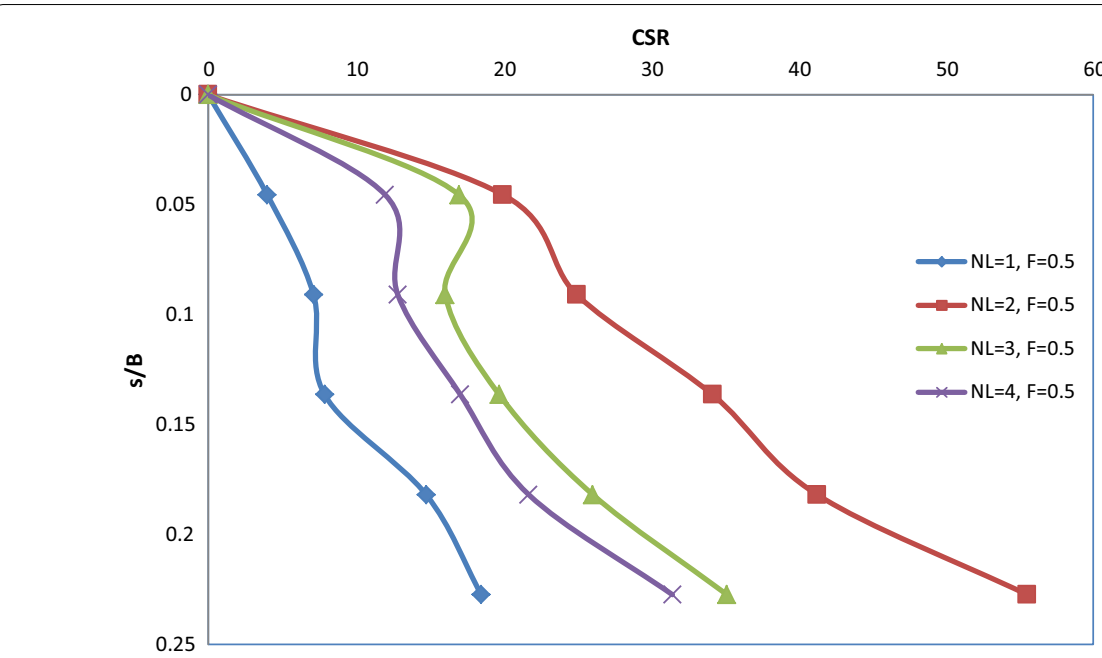

Fig. 8 CSR with s/B for different layer configuration under $F=0.5 \mathrm{~Hz}$ and $C P=100 \mathrm{kPa}$

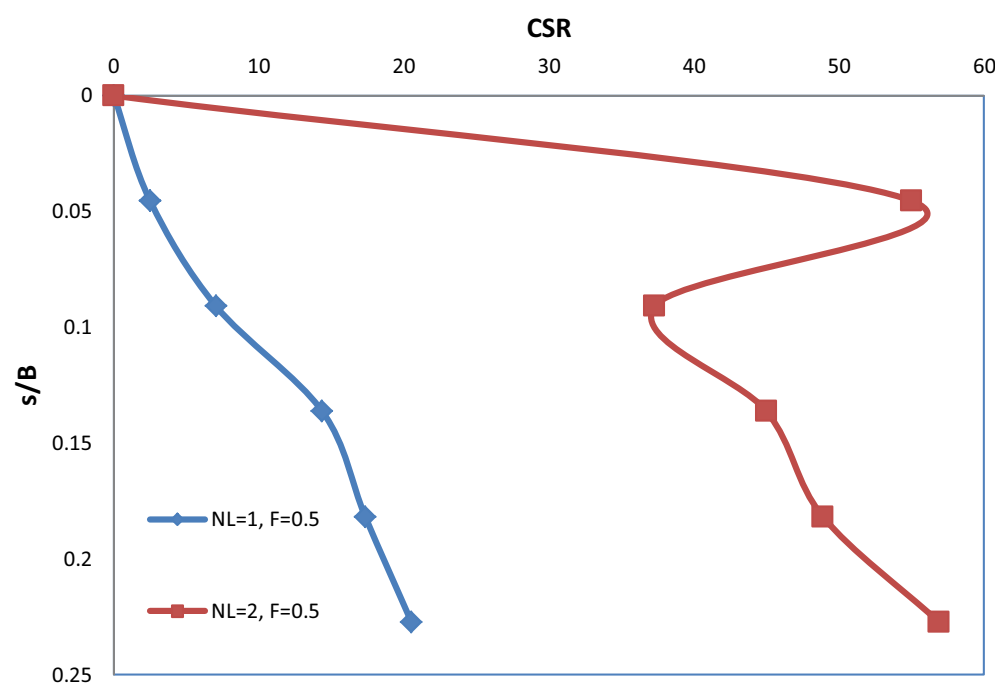

Fig. 9 CSR with $s / B$ for different layer configuration under $F=0.5 \mathrm{~Hz}$ and $C P=300 \mathrm{kPa}$

\section{Effect of frequency and amplitude of loading on cyclic settlement ratio}

To analyze the effect of introduction of different number of layers of coir mat and to determine optimum number of layers which is more effective in increasing the cyclic resistance of reinforced sand, the cyclic stress ratio (CSR) was calculated for different number of cycles. Table 4 shows typical calculated values of CSR corresponding to $\mathrm{NL}=1, \mathrm{CP}=100 \mathrm{kPa}$ and varying frequencies. Figure 8 shows variation of CSR with s/B under different frequencies and different cyclic pressure obtained for different layer configurations. Majority of the trend in results indicate that CSR increases with increase in $\mathrm{s} / \mathrm{B}$ ratio for all layer configurations. It can also be seen that for a given s/B ratio maximum CSR is obtained for $\mathrm{NL}=2$ layers and marginal variations have been indicated with regard to CSR values for $\mathrm{NL}=3$ and 4 layers. Figure 9 shows values of CSR with s/B for single and double Layer Configuration under $\mathrm{F}=0.5 \mathrm{~Hz}$ and $\mathrm{CP}=300 \mathrm{kPa}$. 
However, at higher frequency and at higher cyclic pressure CSR reaches maximum with a subsequent reduction in CSR with increase in $\mathrm{s} / \mathrm{B}$ ratio. This trend in higher CSR at lower $\mathrm{s} / \mathrm{B}$ ratio when frequency and amplitude of loading is higher is due to the effect of particle being rearranged under initial rigorous shaking to achieve higher compaction at lower values of settlement- leading to higher initial cyclic resistance. Continued shaking ultimately breaks the confining effect provided by compacted sand and hence CSR reduces and shows decreasing trend with increasing s/B. However, CSR values for all s/B ratios lies in the range higher than 50 indicating cyclic resistance of reinforced sand bed is significantly high when compared with cyclic resistance of unreinforced sand.

To confirm the above trend in variation of CSR, the stiffness of reinforced sand bed were also calculated in terms of cycles per $\mathrm{mm}$. The calculated values of stiffness obtained for both unreinforced and reinforced sand with $\mathrm{NL}=1,2,3$ and 4 layers and at $\mathrm{CP}=100,200$ and $300 \mathrm{kPa}$ at a constant frequency of $0.5 \mathrm{~Hz}$.

Figure 10 shows typical variation of stiffness with number of cycles for different layer configuration under different excitation parameters. It can be seen that stiffness increases with increase in number of cycles and stiffness of unreinforced sand is significantly lower when compared with reinforced sand. The trend in results indicates only marginal variation in stiffness when sand is reinforced with $\mathrm{NL}=3$ and 4 layers. Further the stiffness obtained corresponding to $\mathrm{NL}=3$ and 4 layers is lower than those obtained for $\mathrm{NL}=2$ layers at all excitation parameters of cyclic loading but greater than that obtained for unreinforced sand.

Analysis of trend in results in terms of CSR and stiffness of reinforced sand bed have indicated the following: (i) The performance of the reinforced sand bed is better than unreinforced sand bed under cyclic loading and at all excitation parameters such as frequency and amplitude of loading.(ii) Increase in frequency and amplitude of cyclic loading increases the settlement of the footing, but the corresponding settlement obtained for unreinforced sand is significantly larger-indicating reinforcing sand using grid/mat type of reinforcement increases the efficiency and performance of foundations to resist cyclic or repeated loads. (iii) The optimum number of layers corresponds to $\mathrm{NL}=2$

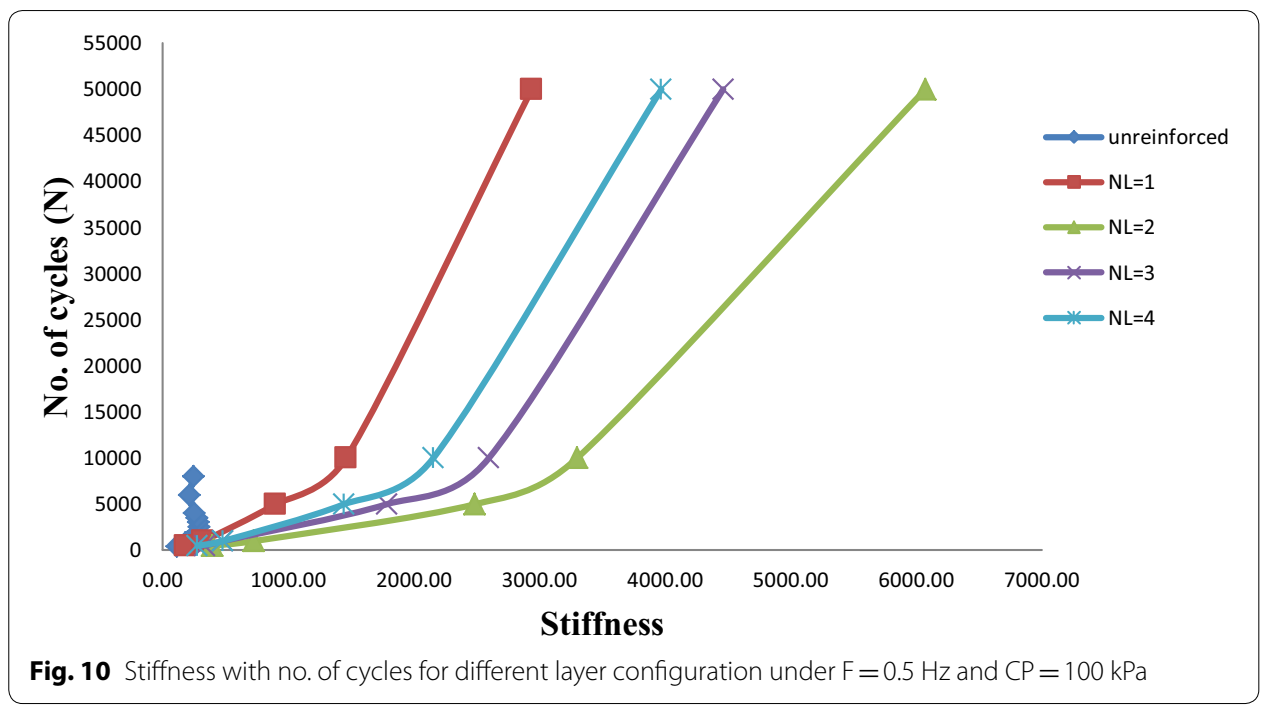


which causes significant retardation in settlement and also causes significant increase in number of cycles required to cause yielding of soil. (iv) The optimum number of layers required for cyclic loading is also same as that required for static loading, (as per studies conducted by Binquet and Lee [26]; Akinmusuru and Akinbolade [27]). (v) The performance of reinforced sand bed mainly depends on location of the reinforcement.

By placing $\mathrm{NL}=2$ layers, reinforcement are enclosed in the shear zone below the footing and helps to restrain the soil deformation that occurs in the failure zone to a great extent. Hence efficiency of reinforced sand bed under cyclic loading becomes maximum under all excitation parameters with $\mathrm{NL}=2$ layers.

Two important observations from this plot are: Introducing of Reinforcement, increased with the number of layers at all confining pressures; Increase in confining pressure resulted in the decrease in the benefit for any precise amount of reinforcement. These results are in accord with the observations by Haeri et al. [28]. Increase in the performance due to reinforcement is nonlinear with the increase in quantity of reinforcement, the nonlinearity decreasing with the increase in confining pressure.

\section{Conclusions}

The behavior of model footings resting on coir mat reinforced sand bed as well as unreinforced sand bed was studied. Cyclic load was applied till sufficient number of load cycles was reached to cause yielding of soil. Reinforcement parameters such as number of layers and excitation parameters such as frequency and amplitude of cyclic loading were studied by compact the sand to a relative density of $60 \%$. Based on the analysis of test results the following conclusions are drawn:

1. Structures that are sensitive to settlement, as well as structures that are subjected to repeated or cyclic loading, the load carrying capacity can be increased and the settlement can be decreased to a much lower magnitude by reinforcing the soil using mat/ grid form of reinforcement.

2. The rate of settlement, magnitude of settlement, the number of cycles required to cause yielding of soil are a function of frequency and amplitude of cyclic loading.

3. For given amplitude of cyclic loading, increase in number of layers of reinforcement, decreases the settlement as well as the number of load cycles required to cause yielding increases. Similar trend has been obtained for a given value of frequency of cyclic load.

4. Under a constant frequency and for a given reinforcement configuration, increase in amplitude of cyclic loading increases the settlement under same number of load cycles. Similarly for constant amplitude of loading, increase in frequency of cyclic load increases the settlement.

5. Increase in amplitude and frequency of cyclic load increases the footing settlement irrespective of increase in number of layers.

6. With increasing number of layers, the number of cycles required to cause failure increases-indicating increase in load carrying capacity of reinforced sand. However, the footing settlement under the same number of cycles increases, with increase in number of layers greater than two layers. Thus the efficiency of the reinforcement is decreased by increase in mass of the reinforcement. 
7. The location of the reinforcement below the footing plays an important role in increasing the performance of reinforced sand bed under cyclic loading. Efficiency of reinforced sand is best when reinforcement is placed in such a way that it is able to intercept the shear failure zone to its maximum thereby causing maximum lateral restraint of deformed zone below the model footing.

8. Variation in terms of cyclic settlement ratio and stiffness of reinforced sand indicates that introduction of the reinforcement increases the stiffness of the sand significantly and hence decreases the settlement when compared to the reinforcement.

9. The rate of footing settlement is significantly low at lower load cycles (between 0 and 1000 cycles) for reinforced sand when compared with unreinforced sand.

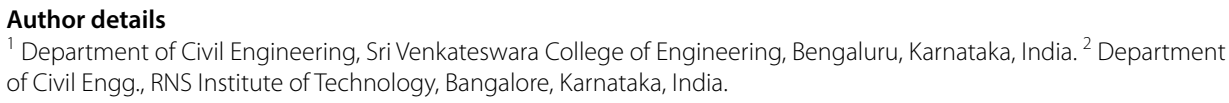

\section{Authors' contributions}

RS and MTPK carried out investigation on shear strength parameters of coir fiber reinforced sand and coir mat reinforced sand. Both authors read and approved the final manuscript.

\section{Competing interest}

The authors declare that they have no competing interests.

\section{Ethics approval and consent to participate}

Not applicable

\section{Publisher's Note}

Springer Nature remains neutral with regard to jurisdictional claims in published maps and institutional affiliations.

Received: 6 May 2017 Accepted: 30 May 2018

Published online: 11 June 2018

\section{References}

1. Vesic AS (1973) Analysis of ultimate loads of shallow foundations. Soil Mech Found Division ASCE 94(SM3):661-688

2. Gray DH, Ohashi H (1983) Mechanics of fiber reinforcement in sand. J Geotech Eng 109(3):335-353

3. Chang DT, Wang WJ, and Wang YH. (1998) Laboratory study of the dynamic test system on geogrid reinforced subgrade-soil. In: Proc. 6th I.C. on geosynthetics, vol 2 Atlanta, USA, pp 967-970

4. Gray DH, Al-Refeai T (1986) Behavior of fabric-versus fiber-reinforced sand. Int J Geotech Eng 112:804-820

5. Guido VA, Chang DK, Sweeney MA (1986) Comparison of geogrid and geotextile reinforced earth slabs. Can Geotech J 23:435-440

6. Raymond GP, Comos FE (1978) Repeated load testing of a model plane strain footing. Can Geotech J 15:190-201

7. Chen X, Zhang J, Li Z (2014) Shear behaviour of a geogrid-reinforced coarse-grained soil based on large-scale triaxial tests. Geotext Geomembr 42(4):312-328

8. Das BM, Shin EC (1994) Strip foundation on geogrid-reinforced clay: behavior under cyclic loadings. Geotext Geomembr 13:657-667

9. Gray DH, Maher MH (1989) Admixture stabilization of sands with discrete, randomly distributed fibers. In: Proc., XII int. conf. on soil mech. and found. engg, Rio de Janeiro, Brazil

10. Raymond GP (2002) Reinforced ballast behavior subjected to repeated load. Geotext Geomembr 20:39-61

11. El Sawwaf M, Nazir AK (2010) Behavior of repeatedly loaded rectangular footings resting on reinforced sand. Alexandria Eng J 49(4):349-356. https://doi.org/10.1016/j.aej.2010.07.002

12. Omar MT, Das BM, Puri VK, Yen SC (1993) Ultimate bearing capacity of shallow foundations on sand with geogrid reinforcement. Can Geotech J 30:545-549

13. Das BM, Omar MT (1994) The effects of foundation width on model tests for the bearing capacity of sand with geogrid reinforcement. Geotech Geol Eng 12:133-141

14. Das BM, Puri VK, Omar MT, Evgin E. (1996) Bearing capacity of strip foundation on geogrid reinforced sand-scale effects in model tests. In: Proceedings of the sixth international conference on offshore and polar engineering, vol I, Los Angeles, USA, pp 527-530

15. El Sawwaf M (2007) Behavior of strip footing on geogrid-reinforced sand over a soft clay slope. Geotext Geomembr 25:50-60

16. El Sawwaf M (2009) Experimental and numerical study of eccentrically loaded strip footings resting on reinforced sand. J Geotech Geoenviron Eng 135(10):1509-1518 
17. Jewell RA (1980) Some effects of reinforcement on the mechanical behaviour of soils, Ph.D. thesis. University of Cambridge, England

18. McGown A, Yeo KC, Yogarajah I (1990) Identification of a dynamic interlock mechanism. In: Proceedings International Conference on Reinforced Soil. Thomas Telford, London, UK, pp 377-380

19. Shin EC, Kim DH, Das BM (2002) Geogrid-reinforced railroad bed settlement due to cyclic load. Geotech Geol Eng 20:261-271

20. Moghaddas Tafreshi SN, Dawson AR (2010) Comparison of bearing capacity of a strip footing on sand with geocell and with planar forms of geotextile reinforcement. Geotext Geomembr 28(1):72-84

21. Naeini SA, Gholampoor N (2014) Cyclic behaviour of dry silty sand reinforced with a geotextile. Geotext Geomembr 42(6):611-619

22. Sridhar R, Prathapkumar MT (2016) Comparison on shear strength of coir mat and coir fiber reinforced sand. Electr J Geotech Eng 22(03):1015-1023

23. East wood W. (1953) The factors which affect the natural frequency of vibration of foundations, and the effect of vibrations on the bearing power of foundations on sand. Struct Eng 31(3)

24. Werkmeister S, Steven BD, Alabaster DJ, Arnold G, Oeser M. (2005) 3D Finite element analysis of accelerated pavement test results from New Zealand's CAPTIF facility, bearing capacity of roads, railways and airfields. In: Proceedings of the 7th international symposium on the bearing capacity of roads and airfields (BCRA), June 24-26, Trondheim

25. Moghaddas Tafreshi SN, Khalaj O (2008) Laboratory tests of small-diameter HDPE pipes buried in reinforced sand under repeated load. Geotext Geomembr 26(2):145-163

26. Binquet J, Lee KL (2002) Bearing capacity tests on reinforced earth slabs. J Geotech Eng Div ASCE 101:1241-1255

27. Akinmusuru JO, Akinbolade JA (1981) Stability of loaded footings on reinforced soil. J Geotech Eng Div ASCE 107(6):819-827

28. Haeri SM, Noorzad R, Oskoorouchi AM (2000) Effect of geotextile reinforcement on the mechanical behaviour of sand. Geotext Geomembr 18(6):385-402

\section{Submit your manuscript to a SpringerOpen ${ }^{\circ}$ journal and benefit from:}

- Convenient online submission

Rigorous peer review

- Open access: articles freely available online

- High visibility within the field

- Retaining the copyright to your article

Submit your next manuscript at $\mathbf{s p r i n g e r o p e n . c o m ~}$ 